\title{
Synthesis and Structure Determination of $\mathrm{AgScP}_{2} \mathrm{Se}_{6}, \mathrm{AgErP}_{2} \mathrm{Se}_{6}$ and $\mathrm{AgTmP}_{2} \mathrm{Se}_{6}$
}

\author{
Arno Pfitzner*[a] and Stefan Seidlmayer ${ }^{[a]}$ \\ Dedicated to Professor Reinhard Nesper on the Occasion of His 60th Birthday
}

Keywords: Selenium; Silver; Scandium; Thulium; Layered compounds

Abstract. $\mathrm{AgScP}_{2} \mathrm{Se}_{6}, \mathrm{AgErP}_{2} \mathrm{Se}_{6}$ and $\mathrm{AgTmP}_{2} \mathrm{Se}_{6}$ were obtained by high temperature reaction of stoichiometric amounts of the elements in evacuated silica ampoules. They crystallize in the space group $P \overline{3} 1 c, Z=2$ with the lattice constants $a=6.463(1) \AA$, $c=13.349(1) \AA\left(\mathrm{AgScP}_{2} \mathrm{Se}_{6}\right), a=6.578(1) \AA, c=13.410(2) \AA$ $\left(\mathrm{AgErP}_{2} \mathrm{Se}_{6}\right)$, and $a=6.567(1) \AA, c=13.422(1) \AA\left(\mathrm{AgTmP}_{2} \mathrm{Se}_{6}\right)$. The crystal structures of $\mathrm{AgScP}_{2} \mathrm{Se}_{6}$ and $\mathrm{AgErP}_{2} \mathrm{Se}_{6}$ were refined from merohedrally twinned crystals. No twinning was observed for $\mathrm{AgTmP}_{2} \mathrm{Se}_{6}$. The crystal structures are isotypic and can be described as a variant of the $\mathrm{CdI}_{2}$ structure type. Thus, selenium atoms are hexagonally close packed. The octahedral voids of every second layer are occupied by $\mathrm{Ag}, M^{3+}(M=\mathrm{Sc}, \mathrm{Er}, \mathrm{Tm})$, and $\mathrm{P}_{2}$ dumbbells in an ordered fashion. The crystal structures are isotypic to $\mathrm{AgScP}_{2} \mathrm{~S}_{6}$ and $\mathrm{AgInP}_{2} \mathrm{~S}_{6}$.

\section{Introduction}

Hexachalcogenohypodiphoshates have attracted some attention in the past because of their interesting physical and chemical properties. $\mathrm{Ni}_{2} \mathrm{P}_{2} \mathrm{~S}_{6}$ for example has been investigated for its potential use in high-energy lithium batteries [1-4], and $\mathrm{Sn}_{2} \mathrm{P}_{2} \mathrm{~S}_{6}$ for its strong non-linear-optical (NLO) effects [5]. Hexachalcogenohypodiphoshates form a vast family of compounds, which can roughly be divided into two major groups. The first group exhibits layered structures and the second group crystallizes in network structures. Each group can be further subdivided into subgroups based on the structure type, the elemental composition or the oxidation state of the metal ions. The most investigated subgroups are the $M_{2} \mathrm{P}_{2} Q_{6}$ compounds $(Q=\mathrm{S}, \mathrm{Se})$, where $M$ denotes a divalent metal cation as iron, nickel, cadmium, zinc, manganese, tin, lead, barium or strontium, and the group $M^{\mathrm{I}} M^{\mathrm{III}} \mathrm{P}_{2} Q_{6}$, where $M^{\mathrm{I}}$ is a monovalent cation as sodium, potassium, silver or copper, and $M^{\mathrm{III}}$ is a trivalent cation as chromium, vanadium, aluminum or indium. $M_{2} \mathrm{P}_{2} Q_{6}$ compounds containing transition metals crystallize with layer structures. On the other hand, divalent maingroup metal containing hexachalcogenohypodiphosphates tend to form network structures. The transition metal layered structures were investigated for their capability to intercalate various guest species into the van der Waals-

* Prof. Dr. A. Pfitzner Fax: +49-941-814551

E-Mail: arno.pfitzner@chemie.uni-regensburg.de

[a] Institut für Anorganische Chemie

Universität Regensburg

93040 Regensburg, Germany gaps [6-9]. Among the network structures $\mathrm{Sn}_{2} \mathrm{P}_{2} \mathrm{~S}_{6}$ is the most intriguing example; the investigations focus on its strong (NLO) properties [10-12]. In the $M^{\mathrm{I}} M^{\mathrm{III}} \mathrm{P}_{2} Q_{6}$ family, the alkali metal compounds usually form network structures, e.g. $\mathrm{NaV}_{0.84} \mathrm{P}_{2} \mathrm{~S}_{6}$ or $\mathrm{KSbP}_{2} \mathrm{Se}_{6}[13,14]$. When $M^{\mathrm{I}}$ is a monovalent transition metal $\left(\mathrm{Cu}^{1+}, \mathrm{Ag}^{1+}\right)$, layered structures are often observed, e.g. for $\mathrm{AgScP}_{2} \mathrm{~S}_{6}$ [15], $\mathrm{AgInP}_{2} \mathrm{~S}_{6}$ [16], $\mathrm{CuCrP}_{2} \mathrm{Se}_{6}$ and $\mathrm{CuInP}_{2} \mathrm{Se}_{6}$ [17]. Only a general trend is observable for structure prediction, the larger the cations, the more pronounced is the tendency to form network structures. Obviously, this is not satisfactory and more systematic structural studies need to be made and more dedicated factors for structure type formation have to be found.

\section{Results and Discussion}

$\mathrm{AgScP}_{2} \mathrm{Se}_{6}, \mathrm{AgErP}_{2} \mathrm{Se}_{6}$, and $\mathrm{AgTmP}_{2} \mathrm{Se}_{6}$ are isotypic to $\mathrm{AgScP}_{2} \mathrm{~S}_{6}$ [15]. The crystal structures can be derived from the $\mathrm{CdI}_{2}$ structure type. Herein, their structures will be discussed by using $\mathrm{AgScP}_{2} \mathrm{Se}_{6}$ as a representative. The description holds for the erbium and the thulium compound just by replacing scandium by the respective rare earth metals.

Selenium atoms form a close packed hexagonal arrangement, in which the octahedral voids of every second layer are occupied in an ordered way by silver, scandium and $\mathrm{P}_{2}$ dumbbells. The $M \mathrm{Se}_{6}$-octahedra and $\mathrm{P}_{2} \mathrm{Se}_{6}$-octahedra within a layer are connected through common edges and form a triangular lattice with an AB-type layer stacking, see Figure 1. 


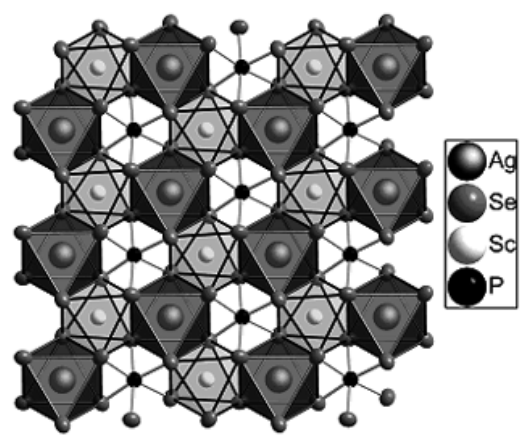

Figure 1. View on (001) of the crystal structure of $\mathrm{AgScP}_{2} \mathrm{Se}_{6}$. The cations in the octahedral voids of the selenium layers are trigonally ordered. Ellipsoids enclose $99 \%$ probability.

In all compounds, the $\left[\mathrm{P}_{2} \mathrm{Se}_{6}\right]^{4-}$ ion has staggered conformation, which is typically observed in hexachalcogenohypodiphosphates. The torsion angles $(\mathrm{Se}-\mathrm{P}-\mathrm{P}-\mathrm{Se})$, selected bond angles and bond lengths $d(\mathrm{P}-\mathrm{P})$ and $d(\mathrm{P}-\mathrm{Se})$ are listed in Table 1.

Table 1. Bond lengths $/ \AA$ and angles $/{ }^{\circ}$ in the $\left[\mathrm{P}_{2} \mathrm{Se}_{6}\right]^{4-}$ units.

\begin{tabular}{rlllll}
\hline Compound & $(\mathrm{Se}-\mathrm{P}-\mathrm{P}-\mathrm{Se})$ & $(\mathrm{P}-\mathrm{P}-\mathrm{Se})$ & $(\mathrm{Se}-\mathrm{P}-\mathrm{Se})$ & $d(\mathrm{P}-\mathrm{P})$ & $d(\mathrm{P}-\mathrm{Se})$ \\
\hline $\mathrm{AgScP}_{2} \mathrm{Se}_{6}$ & $172.21(6)$ & $107.20(2)$ & $111.64(2)$ & $2.205(3)$ & $2.192(1)$ \\
& $52.20(8)$ & & & & \\
& $-67.81(8)$ & & & & \\
$\mathrm{AgErP}_{2} \mathrm{Se}_{6}$ & $176.87(4)$ & $107.77(1)$ & $111.11(1)$ & $2.230(2)$ & $2.188(1)$ \\
& $56.87(6)$ & & & & \\
$\mathrm{AgTmP}_{2} \mathrm{Se}_{6}$ & $-63.14(5)$ & & & & \\
& $176.5(1)$ & $108.00(3)$ & $110.90(3)$ & $2.215(6)$ & $2.192(2)$ \\
& $56.5(1)$ & & & & \\
& $-63.5(1)$ & & & & \\
\hline
\end{tabular}

The $\mathrm{P}-\mathrm{PSe}_{3}$-tetrahedra have bond angles close to the ideal tetrahedron angle with values ranging from $110.90^{\circ}$ to $111.64^{\circ}$ for the angles $(\mathrm{Se}-\mathrm{P}-\mathrm{Se})$ and $107.20^{\circ}$ to $108.00^{\circ}$ for the angles $(\mathrm{P}-\mathrm{P}-\mathrm{Se})$. The bond lengths $d(\mathrm{P}-\mathrm{P})$ are close to the usual value of $2.21 \AA$ for $\mathrm{P}-\mathrm{P}$ single bonds. The distances $d(\mathrm{P}-\mathrm{Se})$ are equal within the threefold standard deviations and vary between $2.188 \AA$ in $\mathrm{AgErP}_{2} \mathrm{Se}_{6}$, and $2.192 \AA$ in $\mathrm{AgTmP}_{2} \mathrm{Se}_{6}$ and $\mathrm{AgScP}_{2} \mathrm{Se}_{6}$, respectively.

The silver atoms are hexacoordinate in slightly distorted octahedra with bond lenghts $d(\mathrm{Ag}-\mathrm{Se})$ of $2.899 \AA$ and $2.909 \AA$. The angles $(\mathrm{Se}-\mathrm{Ag}-\mathrm{Se})$ deviate only slightly from $90^{\circ}$. The large displacement ellipsoids for the silver atoms are commonly observed in $\operatorname{Ag} M \mathrm{P}_{2} \mathrm{~S}_{6}$ compounds and generally for $d^{10}$-ions (e.g. silver, copper, gold, zinc, cadmium, mercury). They are due to a second order Jahn-Tellereffect $[18,19]$.

The $M^{\mathrm{III}}$ atoms are also hexacoordinate. However, the octahedra $M^{\mathrm{III}} \mathrm{Se}_{6}$ show slightly larger distortions than the octahedra $\mathrm{AgSe}_{6}$. The corresponding bond lengths are $d(\mathrm{Sc}-\mathrm{Se})=2.709 \AA, \quad d(\mathrm{Tm}-\mathrm{Se})=2.825 \AA, \quad$ and $d(\mathrm{Er}-\mathrm{Se})=2.834 \AA$, see Table 2 . These distances compare well to those observed in binary selenides of scandium, erbium, and thulium.
Table 2. Selected bond lengths $/ \AA$ and angles $/{ }^{\circ}$ for $\mathrm{AgSe}_{6}$ and $M^{\mathrm{III}} \mathrm{Se}_{6}$ octahedra.

\begin{tabular}{lllll}
\hline Compound & $(\mathrm{Se}-\mathrm{Ag}-\mathrm{Se})$ & $\left(\mathrm{Se}-M^{\mathrm{III}}-\mathrm{Se}\right)$ & $d(\mathrm{Ag}-\mathrm{Se})$ & $d\left(M^{\mathrm{III}}-\mathrm{Se}\right)$ \\
\hline $\mathrm{AgScP}_{2} \mathrm{Se}_{6}$ & $87.30(2)$ & $87.30(2)$ & $2.899(1)$ & $2.709(1)$ \\
& $92.31(2)$ & $92.31(2)$ & & \\
& $93.09(2)$ & $93.09(2)$ & & \\
$\mathrm{AgErP}_{2} \mathrm{Se}_{6}$ & $86.36(1)$ & $84.61(1)$ & $2.909(1)$ & $2.834(1)$ \\
& $91.84(1)$ & $92.11(1)$ & & \\
& $95.49(1)$ & $98.90(1)$ & & \\
& $177.35(1)$ & $174.97(1)$ & & \\
$\mathrm{AgTmP}_{2} \mathrm{Se}_{6}$ & $86.30(2)$ & $84.35(2)$ & $2.909(1)$ & $2.825(1)$ \\
& $93.10(2)$ & $92.40(3)$ & & \\
& $95.34(2)$ & $99.12(3)$ & & \\
& $177.64(2)$ & $175.01(2)$ & & \\
\hline
\end{tabular}

The height of the van der Waals gap is about $3.15 \AA$, whereas the height of the selenium double layers, which are occupied by the cations, is about $3.55 \AA$. The cations in the $a-b$-layers are ordered by occupying edge-sharing octahedra, which form a triangular honeycomb lattice. Thus distances between equal cations are optimized. The crystal structure of $\mathrm{AgScP}_{2} \mathrm{Se}_{6}$ is displayed in Figure 1 and Figure 2.

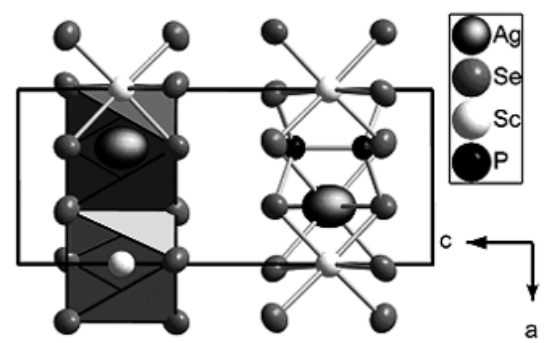

Figure 2. View on the $a-c$ plane of $\mathrm{AgScP}_{2} \mathrm{Se}_{6}$. The van der Waalsgap has a height of about $3.15 \AA$. Coordination octahedra are drawn for one silver and one scandium atom. Ellipsoids represent $99 \%$ probability.

\section{Conclusions}

$\mathrm{AgScP}_{2} \mathrm{Se}_{6}, \mathrm{AgErP}_{2} \mathrm{Se}_{6}$, and $\mathrm{AgTmP}_{2} \mathrm{Se}_{6}$ are three new hexaselenohypodiphosphates with a layered structure of the $\mathrm{AgInP}_{2} \mathrm{~S}_{6}$ structure type. $\mathrm{AgScP}_{2} \mathrm{Se}_{6}$ has an optical bandgap of $1.55 \mathrm{eV}$. Preliminary impedance spectroscopic investigations show no silver ion conductivity.

\section{Experimental Section}

\section{Synthesis}

$\mathrm{AgScP}_{2} \mathrm{Se}_{\mathbf{6}}$ was prepared by annealing stoichiometric amounts of the pure elements in evacuated silica ampoules at $650{ }^{\circ} \mathrm{C}$ for 17 days. The phase pure product was obtained as a brown powder and very small hexagonal shaped orange platelets. X-ray powder diffraction data of the bulk material confirmed its purity.

$\operatorname{AgErP}_{2} \mathrm{Se}_{\mathbf{6}}$ was obtained by annealing stoichiometric amounts of the pure elements in evacuated silica ampoules at $600{ }^{\circ} \mathrm{C}$ for 4 days. 
Table 3. Crystallographic data and structure refinement summary for $\mathrm{AgScP}_{2} \mathrm{Se}_{6}, \mathrm{AgErP}_{2} \mathrm{Se}_{6}$, and $\mathrm{AgTmP} \mathrm{Pe}_{6}$. Lattice constants were taken from powder data refinements [24].

\begin{tabular}{|c|c|c|c|}
\hline Empirical formula & $\mathrm{AgScP}_{2} \mathrm{Se}_{6}$ & $\mathrm{AgErP}_{2} \mathrm{Se}_{6}$ & $\mathrm{AgTmP}_{2} \mathrm{Se}_{6}$ \\
\hline Formula weight $/ \mathrm{g} / \mathrm{mol}$ & 688.54 & 810.83 & 812.50 \\
\hline Temperature /K & & $298(2)$ & \\
\hline Wavelength $/ \AA$ & & $0.71073\left(\right.$ Mo $\left.K_{\alpha}\right)$ & \\
\hline Crystal system, space group & trigonal, $P \overline{3} 1 c$ & trigonal, $P \overline{3} 1 c$ & trigonal, $P \overline{3} 1 c$ \\
\hline $\mathrm{a} / \mathrm{A}$ & $6.463(1)$ & $6.578(1)$ & $6.567(1)$ \\
\hline $\mathrm{c} / \AA$ & $13.349(1)$ & $13.410(2)$ & $13.422(2)$ \\
\hline Volume $/ \AA^{3}$ & $482.93(3)$ & $502.6(1)$ & $501.27(9)$ \\
\hline $\mathrm{Z}$ & 2 & 2 & 2 \\
\hline Calculated density $/ \mathrm{g} / \mathrm{cm}^{3}$ & 4.735 & 5.358 & 5.383 \\
\hline$\mu / \mathrm{mm}^{-1}$ & 25.594 & 32.210 & 32.773 \\
\hline Crystal color and shape & orange-brown platelet & dark-brown platelet & dark-brown platelet \\
\hline Crystal size $/ \mathrm{mm}$ & $0.04 \times 0.05 \times 0.015$ & $0.12 \times 0.12 \times 0.03$ & $0.11 \times 0.10 \times 0.07$ \\
\hline Diffractometer Type & STOE IPDS I & STOE IPDS I & STOE IPDS I \\
\hline Index ranges & $\begin{array}{l}-8 \leq h \leq 8 \\
-8 \leq k \leq 8 \\
-17 \leq l \leq 17\end{array}$ & $\begin{array}{l}-8 \leq h \leq 8 \\
-8 \leq k \leq 8 \\
-16 \leq l \leq 16\end{array}$ & $\begin{array}{l}-8 \leq h \leq 7 \\
-8 \leq k \leq 8 \\
-17 \leq l \leq 17\end{array}$ \\
\hline Min. $\Theta /^{\circ}$ & 3.05 & 3.04 & 3.04 \\
\hline $\operatorname{Max} . \Theta /^{\circ}$ & 27.88 & 26.69 & 27.85 \\
\hline Reflections (collected / unique) & $5119 / 394$ & $6968 / 362$ & $4480 / 407$ \\
\hline$R_{\text {int }}, R_{\sigma}$ & $0.0841,0.0335$ & $0.0432,0.0142$ & $0.1242,0.0538$ \\
\hline Data / restraints / parameters & 394 / 0 / 19 & $362 / 0 / 19$ & $407 / 0 / 17$ \\
\hline GooF & 1.152 & 1.167 & 1.025 \\
\hline$R_{1}, w R_{2}$ (all reflections) & $0.0453,0.0764$ & $0.0196,0.0356$ & $0.0580,0.0785$ \\
\hline Extinction coefficient & $0.0087(11)$ & $0.0019(3)$ & - \\
\hline Twin matrix & $\overline{1} 00,0 \overline{1} 0,001$ & $\overline{1} 00,0 \overline{1} 0,001$ & - \\
\hline Twin fractions & $0.967(2): 0.033(2)$ & $0.742(2): 0.258(2)$ & - \\
\hline
\end{tabular}

The product was a mixture of a dark brown powder and small dark-brown platelets. Phase pure $\mathrm{AgErP}_{2} \mathrm{Se}_{6}$ was not obtained. Powder diffraction data showed small amounts of $\mathrm{Er}_{2} \mathrm{Se}_{3}$ as a byproduct.

$\operatorname{AgTmP}_{2} \mathrm{Se}_{6}$ results from annealing stoichiometric amounts of the pure elements in evacuated silica ampoules at $550{ }^{\circ} \mathrm{C}$ for 5 days. The product was a dark-brown powder and dark-brown small platelets. $\mathrm{Tm}_{2} \mathrm{Se}_{3}$ and $\mathrm{Ag}_{4} \mathrm{P}_{2} \mathrm{Se}_{6}$ always were found as by-products.

\section{Powder Diffraction}

X-ray powder diffraction data were recorded with a STOE STADI $\mathrm{P}$ diffractometer with a $\mathrm{Ge}(111)$ monochromator providing $\mathrm{Cu}-K_{\alpha 1}$ radiation. Lattice constants were refined from the powder patterns and then used for the single crystal structure refinements in the last cycles, see Table 3.

\section{Single-Crystal X-ray Diffraction}

Single crystals suitable for crystal structure determination were mounted on glass fibers and checked for their quality by Weissenberg photographs. X-ray diffraction intensities were collected on a STOE IPDS at 293(2) K using Mo- $K_{\alpha}$ radiation. The measurements were performed in an incremental scanning mode. Data were corrected for Lorentz and polarization effects. Absorption was numerically corrected after an optimization of the crystal shape with the X-SHAPE [20] routine. Further details of the measurements and basic crystallographic information are collected in Table 3. The program package WinGX [21], using SHELXS-97 and SHELXL-97 [22, 23] was used for solving and refining the crystal
Table 4. Refined atomic parameters and equivalent isotropic displacement parameters $U_{\text {eq }}$ of the title compounds.

\begin{tabular}{lllllll}
\hline Compound & Atom $\begin{array}{l}\text { Wyckoff } \\
\text { position }\end{array}$ & $y$ & $z$ & $U_{\text {eq }} / \AA^{2}$ \\
\hline $\mathrm{AgScP}_{2} \mathrm{Se}_{6}$ & $\mathrm{Ag} 1$ & $2 \mathrm{~d}$ & $2 / 3$ & $1 / 3$ & $1 / 4$ & $0.0515(5)$ \\
& $\mathrm{Sc} 1$ & $2 \mathrm{a}$ & 0 & 0 & $1 / 4$ & $0.0167(3)$ \\
& $\mathrm{Se} 1$ & $12 \mathrm{i}$ & $0.0229(1)$ & $0.33077(8)$ & $0.11885(5)$ & $0.0154(5)$ \\
& $\mathrm{P} 1$ & $4 \mathrm{f}$ & $1 / 3$ & $2 / 3$ & $0.1674(2)$ & $0.0130(5)$ \\
$\mathrm{AgErP}_{2} \mathrm{Se}_{6}$ & $\mathrm{Ag} 1$ & $2 \mathrm{~d}$ & $2 / 3$ & $1 / 3$ & $1 / 4$ & $0.0643(4)$ \\
& $\mathrm{Er} 1$ & $2 \mathrm{a}$ & 0 & 0 & $1 / 4$ & $0.0184(1)$ \\
& $\mathrm{Se} 1$ & $12 \mathrm{i}$ & $0.02183(6)$ & $0.34516(6)$ & $0.11705(3)$ & $0.0209(1)$ \\
& $\mathrm{P} 1$ & $4 \mathrm{f}$ & $1 / 3$ & $2 / 3$ & $0.1669(1)$ & $0.0148(3)$ \\
$\mathrm{AgTmP}_{2} \mathrm{Se}_{6}$ & $\mathrm{Ag} 1$ & $2 \mathrm{~d}$ & $2 / 3$ & $1 / 3$ & $1 / 4$ & $0.0688(8)$ \\
& $\mathrm{Tm} 1$ & $2 \mathrm{a}$ & 0 & 0 & $1 / 4$ & $0.0244(3)$ \\
& $\mathrm{Se} 1$ & $12 \mathrm{i}$ & $0.0216(2)$ & $0.3439(1)$ & $0.11704(7)$ & $0.0270(3)$ \\
& $\mathrm{P} 1$ & $4 \mathrm{f}$ & $1 / 3$ & $2 / 3$ & $0.1675(3)$ & $0.0206(8)$ \\
\hline & & & & & &
\end{tabular}

structures. The refined atom positions and equivalent isotropic displacements parameters are printed in Table 4 .

For the structure solution and refinement of $\mathrm{AgScP}_{2} \mathrm{Se}_{6}$ and $\mathrm{AgErP}_{2} \mathrm{Se}_{6}$ merohedral twinning according to a twinning matrix $\overline{1} 00,0 \overline{1} 0,001$ had to be taken into account. Thus, the $R$-values dropped from $w R_{2}=0.109$ to $w R_{2}=0.076\left(\mathrm{AgScP}_{2} \mathrm{Se}_{6}\right)$ for a twin ratio of 0.967:0.033. For $\mathrm{AgErP}_{2} \mathrm{Se}_{6}$ the initial $R$-value $w R_{2}=0.614$ dropped significantly to $w R_{2}=0.036$ with a refined twin ratio of 0.742:0.258. No twinning was observed for $\mathrm{AgTmP}_{2} \mathrm{Se}_{6}$.

\section{UVIVis Spectroscopy}

$\mathrm{UV} / \mathrm{Vis}$ data of $\mathrm{AgScP}_{2} \mathrm{Se}_{6}$ were collected with a Bruins instruments Omega 20 two-wave photometer in remission mode. The ob- 
tained data were transformed into absorption spectra by using the Kubelka-Munk function. The value for the band-gap was extrapolated by linear regression of the absorption edge kink. The extrapolated band-gap is $1.55 \mathrm{eV}$.

\section{Thermal Analysis}

DTA measurements were performed in sealed thin walled silica ampoules with a SETARAM TG-DTA 92-16.18. The measurements showed peritectic decomposition for the discussed compounds. Decomposition temperatures are $654{ }^{\circ} \mathrm{C}\left(\mathrm{AgErP}_{2} \mathrm{Se}_{6}\right), 657^{\circ} \mathrm{C}$ $\left(\mathrm{AgTmP}_{2} \mathrm{Se}_{6}\right)$, and $711^{\circ} \mathrm{C}\left(\mathrm{AgScP}_{2} \mathrm{Se}_{6}\right)$, respectively. After the initial heating, a second peak is observed in all samples at $569-572{ }^{\circ} \mathrm{C}$ that is attributed to $\mathrm{Ag}_{4} \mathrm{P}_{2} \mathrm{Se}_{6}$, which could be detected in the powder diffraction patterns.

\section{Acknowledgement}

We thank Gregor Raab and Stephan Eckl for some experimental help and Heike Hack for the UV/Vis measurements.

\section{References}

[1] A. H. Thompson, M. S. Whittingham, Mater. Res. Bull. 1977, 12,741 .

[2] A. Le Méhauté, G. Ouvrard, R. Brec, J. Rouxel, Mater. Res. Bull. 1977, 12, 1191.

[3] G. Giunta, V. Grasso, F. Neri, L. Silipigni, Phys. Rev. B: Condens. Matter 1994, 50, 8189.

[4] V. Manríquez, P. Barahona, D. Ruiz, R. E. Avila, Mater. Res. Bull. 2005, 40, 475.

[5] S. G. Odoulov, A. N. Shumelyuk, U. Hellwig, R. A. Rupp, A. A. Grabar, I. M. Stoyka, J. Opt. Soc. Am. B 1996, 13, 2352.

[6] P. J. S. Foot, N. S. Shaker, Mater. Res. Bull. 1983, 18, 173.
[7] A. Léaustic, J. P. Audière, P. G. Lacroix, R. Clément, L. Lomas, A. Michalowicz, W. R. Dunham, A. H. Francis, Chem. Mater. 1995, 7, 1103.

[8] A. Léaustic, J. P. Audière, D. Cointereau, R. Clément, L. Lomas, F. Varret, H. Constant-Machado, Chem. Mater. 1996, 8, 1954.

[9] I. Lagadic, A. Léaustic, R. Clement, J. Chem. Soc., Chem. Commun. 1992, 1396.

[10] A. Anema, A. Grabar, T. Rasing, Ferroelectrics 1996, 183, 181.

[11] E. Arnautova, E. Sviridov, E. Rogach, E. Savchenko, A. Grekov, Integrated Ferroelectrics 1992, 1, 147.

[12] S. L. Bravina, N. V. Morozovsky, A. K. Kadashchuk, V. S. Manzhara, Ferroelectrics 1997, 192, 197.

[13] S. Coste, E. Gautier, M. Evain, M. Bujoli-Doeuff, R. Brec, S. Jobic, M. G. Kanatzidis, Chem. Mater. 2003, 15, 2323.

[14] J. D. Breshears, M. G. Kanatzidis, J. Am. Chem. Soc. 2000, 122,7839 .

[15] S. Lee, P. Colombet, G. Ouvrard, R. Brec, Inorg. Chem. 1988, 27, 1291.

[16] Z. Ouili, A. Leblanc, P. Colombet, J. Solid State Chem. 1987, $66,86$.

[17] X. Bourdon, V. Maisonneuve, V. B. Cajipe, C. Payen, J. E. Fischer, J. Alloys Compd. 1999, 283, 122.

[18] F. Boucher, M. Evain, R. Brec, J. Alloys Compd. 1994, 215, 63.

[19] L. E. Orgel, J. Chem. Soc. 1958, 4186.

[20] X-SHAPE, Version 2.07, 1997, STOE \& CIE GmbH, Darmstadt.

[21] L. J. Farrugia, Win GX, 1999, Department of Chemistry, Joseph Black Building, University Of Glasgow, Glasgow G12 8QQ.

[22] G. M. Sheldrick, SHELXS-97, 1997, Universität Göttingen.

[23] G. M. Sheldrick, SHELXL-97, 1997, Universität Göttingen.

[24] Further details of the crystal structure investigation are available from the Fachinformationszentrum Karlsruhe, 76344 Eggenstein-Leopoldshafen, Germany (Fax: +49-7247808-666, E-Mail: crysdata@fiz-karlsruhe.de referring to number CSD-420302 ( $\left.\mathrm{AgScP}_{2} \mathrm{Se}_{6}\right), \mathrm{CSD}-420303\left(\mathrm{AgErP}_{2} \mathrm{Se}_{6}\right)$, CSD-420304 ( $\left.\mathrm{AgTmP}_{2} \mathrm{Se}_{6}\right)$, name of the authors and citation of the paper.

Received: December 19, 2008 Published Online: February 27, 2009 